\title{
Por que a economia brasileira não cresce dinâmica e sustentavelmente? Uma análise kaleckiana e keynesiana *
}

\author{
Eduardo Maldonaldo Filho \\ Fernando Ferrari Filho ${ }^{* * *}$ \\ Marcelo Milan ${ }^{* * * *}$
}

\begin{abstract}
Resumo
Este artigo examina a relação, para a economia brasileira, entre a formação bruta de capital fixo e o crescimento econômico. Tendo como referência as teorias keynesianas e kaleckianas, procura-se entender porque a economia brasileira, a despeito da estabilização monetária alcançada com o Plano Real, se encontra estagnada desde os anos 1990. As evidências empíricas mostram uma elevação do investimento por um curto intervalo nos últimos anos, mas em níveis insuficientes para dinamizar o crescimento econômico e ampliar a relação investimento/PIB. A análise econométrica apresenta resultados compatíveis com as interpretações teóricas e aponta para algumas barreiras importantes para o investimento, como as taxas reais de juros elevadas.
\end{abstract}

Palavras-chave: Teoria do investimento; Crescimento econômico; Economia brasileira; Teoria kaleckiana; Teoria keynesiana.

\section{Abstract \\ Why does the Brazilian economy not grow in a dynamic and sustainable way? A Kaleckian and Keynesian analysis}

This article examines the relationship between investment and economic growth in Brazil. In light of the Keynesian and Kaleckian approaches, it aims to understand the stagnation the Brazilian economy has experienced since the 1990s, despite the monetary stabilization achieved with the Real Plan. Empirical evidence shows that investment increased for a period of time in the past few years, but not to the point of getting the economy back on track in terms of high growth rates and higher investmentGDP ratios. The econometric analysis is compatible with the theoretical underpinnings and identifies important issues such as the high real interest rates.

Keywords: Investment theory; Economic growth; Brazilian economy; Kaleckian theory; Keynesian theory.

JEL E12, E22, O54.

\section{Introdução}

Desde a introdução do Plano Real (PR), quando, após um elevado e crônico processo inflacionário observado no Brasil nos anos 1980 e início dos anos 1990, a

* Artigo recebido em 11 de agosto de 2014 e aprovado em 22 de janeiro de 2016.

** Professor Associado do Programa de Pós-Graduação em Economia da Universidade Federal do Rio Grande do Sul (PPGE-UFRGS), Porto Alegre, RS, Brasil. E-mail: eduardo.maldonado@ufrgs.br.

*** Professor Titular do PPGE-UFRGS / Pesquisador do Conselho Nacional de Desenvolvimento Científico e Tecnológico (CNPq), Porto Alegre, RS, Brasil. E-mail: ferrari@ufrgs.br.

**** Professor Adjunto do PPGE-UFRGS, Porto Alegre, RS, Brasil. E-mail: marcelo.milan@ufrgs.br. 
estabilização monetária foi alcançada ${ }^{1}$, a taxa média de crescimento real do PIB, entre 1994 e 2014, ficou ao redor de 3,1\% ao ano e sua performance caracterizou-se por uma dinâmica à la stop and go. Note-se que o desempenho do PIB tem sido ainda mais baixo e volátil a partir da crise do subprime e da "Grande Recessão", a despeito das políticas macroeconômicas contracíclicas implementadas pelas Autoridades Econômicas (AE) para evitar um efeito-contágio das referidas crises sobre a economia brasileira: entre 2009 e 2014 o crescimento médio real do PIB foi da ordem de $2,6 \%$ ao ano.

Isto nos remete à seguinte questão: Por que nos últimos 21 anos, em um contexto de estabilização monetária, o desempenho da atividade econômica brasileira tem sido fraco e não se sustenta, ao contrário do que supõe a teoria convencional? ${ }^{2}$ A pergunta torna-se mais relevante ainda se analisarmos o crescimento da economia brasileira em uma perspectiva de longo prazo: entre 1950 e 2014, o PIB real cresceu, em média, 4,9\% ao ano ${ }^{3}$.

No nosso ponto de vista, o baixo crescimento do PIB nas últimas duas décadas pode ser explicado, em parte, pela baixa performance da formação bruta de capital fixo (FBKF): entre 1994 e 2014, a relação investimento/PIB foi em média $17,4 \%{ }^{4}$, variando entre $15,3 \%$ e $19,5 \%$. Indo nessa direção, o presente artigo tem como objetivo mostrar que o investimento agregado tem sido um dos fatores de restrição para que a economia brasileira tenha um crescimento econômico robusto e sustentável. Para tanto, tendo como referência as teorias kaleckiana e keynesiana do investimento, ou seja, explicitando-se as principiais variáveis determinantes do investimento, procura-se analisar teórica e empiricamente a relação de causalidade entre investimento e PIB para a economia brasileira ao longo do período 1994-2013, visando, assim, apresentar algumas reflexões e considerações sobre o assunto.

Além desta breve introdução, o artigo está dividido em quatro seções: a seção seguinte apresenta uma breve análise da trajetória da economia brasileira no período pós-PR, objetivando, tão somente, descrever o ambiente econômico favorável (ou não) tanto à realização de investimentos quanto à expansão da atividade econômica; a segunda seção apresenta os aspectos centrais das teorias do

(1) Não é demais lembrar que antes do PR a inflação mensal se encontrava ao redor de $50 \%$, ao passo que entre julho de 1994, quando o real foi criado como moeda de curso legal, e dezembro de 2014, a inflação média anualizada brasileira foi da ordem de 7,9\%. Taxa calculada pelos autores tendo como base as informações estatísticas do Ipeadata (2015).

(2) Contextualizar a pergunta na periodização da estabilização monetária, 1994-2014, é pertinente porque a teoria econômica do mainstream costuma argumentar que inflação baixa é uma pré-condição ao crescimento econômico sustentável.

(3) Nas décadas de 1950, 1960, 1970, 1980, 1990 e 2000, as taxas médias anuais do PIB foram, respectivamente, $7,1 \%, 6,1 \%, 8,8 \%, 3,0 \%, 1,9 \%$ e $3,4 \%$. Taxas calculadas pelos autores tendo como base as informações estatísticas do IBGE (2015).

(4) Taxa calculada pelos autores tendo como base as informações estatísticas do Ipeadata (2015). 
investimento em Kalecki e Keynes; a seção três analisa empiricamente os determinantes do investimento bem como a sua relação com o PIB; e a última seção apresenta as reflexões e considerações finais.

\section{Uma breve análise da economia brasileira no período pós-PR}

Como se sabe, a economia brasileira desde o início dos anos 1990 tem tido um comportamento à la stop-and-go, alternando pequenos ciclos de crescimento com desacelerações econômicas, muitas vezes abruptas ${ }^{5}$ : entre 1990 e 1992, o crescimento médio do PIB apresentou um resultado de - 1,3\% ao ano; no período 1993-1994, início do processo de estabilização monetária do PR - cujas fases, digase de passagem, foram (i) o ajuste fiscal proposto ao final de 1993, denominado Fundo Social de Emergência, (ii) a indexação geral da economia por meio da introdução da Unidade Real de Valor e (iii) a reforma monetária, ou seja, substituição do cruzeiro real pelo real -, o PIB cresceu a uma média anual de 4,8\%; entre 1995 e 1999 a atividade econômica arrefeceu-se consideravelmente, com o PIB crescendo a uma média de 2,5\% ao ano; em 2000 o PIB cresceu 4,3\%; entre 2001 e 2003 houve uma forte desaceleração, com o PIB crescendo a uma taxa média de 1,9\% ao ano; entre 2004 e 2008, a economia brasileira voltou a crescer a uma média anual de 4,8\%; em 2009 houve recessão devido ao contágio da crise mundial e o PIB decresceu 0,2\%; em 2010 a economia cresceu a ritmo "chinês", 7,6\%; e finalmente entre 2011 e 2014 o PIB novamente desacelerou, crescendo a uma média de $2,1 \%$ ao ano.

Com a adoção do PR, em 1994, o objetivo de se controlar a crônica e elevada inflação foi atingido, mas, em contrapartida, outros problemas passaram a afligir a economia brasileira entre 1994 e 1999, período em que as âncoras cambial e monetária representavam os alicerces da política econômica para, respectivamente, estabilizarem os preços domésticos e atraírem capitais externos para equilibrar o balanço de pagamentos, quais sejam: vulnerabilidade e fragilidade externa, desequilíbrios fiscais e endividamento público, apesar da orientação no sentido de

(5) Não é demais ressaltar que, por um lado, nos anos 1990, durante os governos de Fernando Collor de Mello, Itamar Franco e Fernando Henrique Cardoso foram implementadas reformas econômicas de cunho neoliberal, semelhantes àquelas identificadas com o Consenso de Washington, bem como foram adotados planos de estabilização centrados em âncoras monetária (Plano Collor) e cambial (PR), visando reduzir e controlar a dinâmica (hiper) inflacionária. Cabe ressaltar que nestes governos, em nosso ponto de vista, o objetivo essencial da política econômica foi a estabilização monetária. Por outro lado, nos anos 2000, mais especificamente a partir dos governos Lula da Silva e Dilma Rousseff, houve uma ligeira inflexão da política econômica - diga-se de passagem, desde 1999 a política macroeconômica passou a ser conduzida pelo tripé metas de inflação, metas de superávit fiscal e flexibilidade cambial -, bem como os programas sociais e a recuperação do poder de compra do salário mínimo, essenciais para o crescimento do setor de consumo não duráveis, e os projetos de investimento de longo prazo, articulados por meio de parcerias público-privadas, passaram a determinar a dinâmica econômica. Nesse particular, os referidos governos parecem ter se preocupado mais com o crescimento e a inclusão social sem, contudo, negligenciar a questão inflacionária. $\mathrm{O}$ fato de o investimento não ter se mantido em níveis elevados em todo o período, apesar desta orientação, é um quebra-cabeça importante. 
austeridade. Estes não somente contribuíram para desencadear uma crise cambial em 1999, mas condicionaram o baixo desempenho do PIB ao longo do período ${ }^{6,7}$.

Nos anos 2000, principalmente a partir do governo Lula da Silva, o crescimento econômico, tímido, porém mais dinâmico do que os das décadas de 1980 e 1990, teve como peculiaridade o processo de redistribuição de renda, ou, pelo menos, a queda do Índice de $\mathrm{Gini}^{8}$, que acabou contribuindo para a expansão da demanda agregada sob a ótica do consumo de bens não duráveis e duráveis. Para tanto, vários fatores contribuíram para que o consumo das famílias contribuísse de forma substancial para o crescimento: (a) a manutenção de taxas relativamente baixas de inflação, que tornou possível romper com o mecanismo de corrosão real dos salários, que mesmo a indexação geral de preços e salários não conseguia evitar; (b) a recuperação do poder de compra do salário mínimo, que aumentou 934\% entre 1995 e 2014, muito acima da taxa de inflação acumulada, que foi de 295,9\% (em termos reais, o salário mínimo cresceu 161,1\%); (c) as transferências governamentais, tais como o "Programa Bolsa Família", voltado às famílias de baixa renda; e (d) maior estímulo ao crédito bancário.

Ademais, a recuperação econômica a partir de 2004 foi puxada, inicialmente, pelo boom de commodities, bem como pela expansão da taxa de investimento decorrente da implementação do Programa de Aceleração do Crescimento (PAC), em $2007^{9}$.

Todavia, os efeitos da crise do subprime foram acentuados sobre a economia brasileira, devido à abrupta e forte reversão nos fluxos de capitais externos e à desaceleração no mercado de crédito doméstico, ocasionando, assim, uma forte redução do consumo e, principalmente, dos investimentos. De fato, o contágio dessa crise foi bastante agudo e rápido: houve fuga de capitais estrangeiros, especialmente os aplicados nos mercados financeiros e na bolsa de valores; a oferta de crédito externo para bancos e firmas (inclusive exportadoras) foi reduzida; ocorreu um substancial aumento das remessas de lucros e dividendos por parte de subsidiárias de empresas multinacionais; o mercado de crédito doméstico foi retraído; e houve "empoçamento" de liquidez no mercado interbancário. Ademais, a vulnerabilidade da economia brasileira agravou-se em função do uso especulativo de derivativos cambiais por parte de algumas empresas exportadoras, que lucravam apostando na continuidade do processo de apreciação cambial.

(6) Para mais detalhes sobre os problemas fiscais, de endividamento público e de desequilíbrios externos decorrentes do PR, bem como as origens e os desdobramentos da crise cambial brasileira, ver: Ferrari Filho e Paula (2003).

(7) No referido período o PIB cresceu, em média, 2,5\% ao ano, bem como a relação FBKF/PIB foi, em média, da ordem de $17,7 \%$.

(8) Entre 2001 e 2012, o Índice de Gini caiu de 0,596 para 0,530.

(9) Entre 2003 e 2008, a média anual da relação FBKF/PIB foi de aproximadamente 16,7\%. 
O Governo, na ocasião, agiu de forma rápida e sinalizou claramente o objetivo de adotar políticas (fiscal, cambial e creditícia) anticíclicas para evitar uma deterioração mais drástica das expectativas, logrando êxito na recuperação econômica no segundo semestre de 2009. Assim sendo, as AE responderam com uma grande variedade de instrumentos, incluindo: medidas de reforço à liquidez do setor bancário (redução no compulsório e criação de incentivos para os grandes bancos comprarem as carteiras de créditos de pequenos bancos); linha temporária de crédito para as exportações; intervenções do Banco Central do Brasil (BCB) no mercado cambial; estímulo à expansão do crédito por parte dos bancos públicos; redução do imposto sobre produtos industrializados (IPI) para automóveis, eletrodomésticos e produtos de construção; aumento do período de concessão do seguro-desemprego; e criação de um programa de construção de moradia popular ("Minha Casa, Minha Vida") ${ }^{10}$.

Em particular, o crescimento da FBKF e do consumo privado contribuíram para a recuperação da economia, restaurando a confiança dos agentes e a ampliação do nível de utilização da capacidade instalada da indústria, o que fez o investimento crescer de $17 \%$ do PIB ( $1^{\circ}$ trimestre de 2009 ) para $20,5 \%$, no terceiro trimestre de 2010.

O governo Dilma Rousseff (2011-2014), por sua vez, foi marcado pela gradual piora no cenário internacional, devido à crise do Euro, à fraca recuperação da economia norte-americana e à desaceleração dos mercados emergentes - a taxa média de crescimento da economia mundial foi de 5,1\% em 2010, 3,8\% em 2011, 3,3\% em 2012 e 3,1\% em 2013 e 2014 (IMF, 2015). Do ponto de vista da condução da política econômica, destacam-se: mudanças no mix e nos instrumentos de política, com uso de medidas macroprudenciais monetárias e cambiais; houve uma forte redução na taxa Selic (de 12,5\%, em julho de 2011, para 7,5\%, em agosto de 2012); e, após a adoção de uma série de medidas regulatórias sobre os fluxos de capitais, inclusive sobre o mercado de derivativos, ocorreu uma depreciação cambial de $25 \%$ (entre agosto de 2011 e maio de 2012). Em 2013 e, especialmente em 2014, a política monetária voltou a ser restritiva, bem como o Governo passou a ser mais cauteloso nas políticas de incentivos fiscais, uma vez que a inflação passou a distanciar-se do centro da meta de 4,5\%: em 2010, 2011 e 2012 a inflação foi, respectivamente, $5,91 \%, 6,5 \%$ e 5,84\%. A ortodoxia monetária e fiscal, todavia, não resultou no arrefecimento da inflação que fechou os anos de 2013 e 2014 em 5,91\% e 6,41\%, respectivamente.

No referido período, a taxa média de crescimento do PIB foi arrefecida para $2,2 \%$ ao ano e a relação média investimento/PIB ficou ao redor de 19,0\%. Diante de

(10) Para um detalhamento das medidas anticíclicas adotadas no Brasil no período 2008-2009, ver: Barbosa Filho (2010). 
tais números, causa surpresa o fato do PIB no primeiro governo de Dilma Rousseff ter apresentado uma baixa média de crescimento, principalmente porque a relação investimento/PIB foi relativamente elevada quando comparada com períodos recentes. Em nosso ponto de vista, o baixo e instável crescimento da economia brasileira entre 2011 e 2014 pode ter resultado tanto de fatores cíclicos ou conjunturais - piora no cenário internacional (redução de preços de commodities, por exemplo) e uma má coordenação de políticas macroeconômicas a partir de 2010 - quanto de fatores tendenciais ou estruturais, incluindo o processo de desindustrialização em curso na economia brasileira (dado os efeitos de encadeamento que o setor manufatureiro tem sobre a economia como um todo). É também importante mencionar que o esgotamento do ciclo de expansão de consumo das famílias, iniciado com a crise do subprime, foi outro fator que contribui para esta performance do PIB no período 2011-2014.

Por fim, duas últimas considerações sobre este breve histórico da economia brasileira a partir do início dos anos 1990: primeiro, observando-se o comportamento das taxas médias anualizadas de crescimento dos componentes da demanda agregada, entre 1999 e 2014, o consumo das famílias cresceu 3,4\%, o investimento cresceu $3,55 \%$, os gastos governamentais elevaram-se $2,6 \%$ e as exportações líquidas apresentaram uma performance negativa de $0,2 \%$. Ademais, analisando-se as referidas taxas médias anualizadas de crescimento dos componentes da demanda agregada, constata-se o seguinte: entre 1999 e 2002 e 2011 e 2014, quando o PIB cresceu, em média, $2,31 \%$ e $2,14 \%$ ao ano, respectivamente, as taxas médias de expansão do investimento foram de $-1,13 \%$ ao ano no primeiro período e $1,93 \%$ ao ano no segundo período; e entre 2003 e 2006 e 2007 e 2010 , quando as taxas médias de crescimento do PIB foram, respectivamente, $3,5 \%$ ao ano e 4,6\% ao ano, a taxa de variação do investimento foi, em média, de 3,23\% entre 2003 e 2006 e de 10,2\% entre 2007 e $2010^{11}$. Em suma, a principal ilação desta consideração final é que parece haver evidências de uma forte relação entre taxas de crescimento do investimento e da atividade econômica.

Segundo, a desaceleração do setor industrial (ou processo de desindustrialização ${ }^{12}$ ), um setor com forte poder de encadeamento para trás e para frente na economia, bem como portador de progresso técnico (portanto, mais capital intensivo), acabou por contribuir para a baixa taxa de investimento da economia no período pós-1990, inviabilizando, assim, um crescimento econômico mais robusto e sustentável.

(11) Médias elaboradas pelos autores a partir de informações estatísticas do IBGE (2015).

(12) Para mais detalhes sobre o processo de desindustrialização brasileira, ver: Nassif (2008) e Oreiro e Feijó (2010). 


\section{Teorias do investimento}

A discussão anterior sugere a existência de uma forte relação entre FBKF e nível de atividade econômica no Brasil nos últimos 20 anos. Assim sendo, para aprofundar essa relação no sentido de observar a dinâmica recente de crescimento e ciclos da economia brasileira, a presente seção discute o processo de investimento em economias capitalistas por meio das visões de Kalecki e Keynes.

\subsection{A visão kaleckiana}

No livro Theory of economic dynamics (1969), Kalecki desenvolveu a teoria do investimento em duas etapas. Na primeira etapa, é exposta a teoria do investimento para uma economia estática, ou seja, para uma economia capitalista, supondo que ela não apresente tendência de crescimento de longo prazo. $\mathrm{Na}$ concepção de Kalecki, esta é uma análise de curto prazo. Na segunda etapa, ele introduz os "fatores de desenvolvimento" incorporando, também, a tendência de crescimento econômico das economias capitalistas. Em outras palavras, a teoria do investimento procura explicar as flutuações cíclicas ao longo de uma trajetória de crescimento econômico ${ }^{13}$.

\subsubsection{A teoria do investimento em uma economia estática}

Inicialmente, é importante relembrar que para Kalecki o montante de capital empresarial (ou seja, de capital próprio) se constituiu no principal determinante do tamanho de uma empresa. Evidentemente que há o reconhecimento de que as empresas também utilizam capital de terceiros, mas Kalecki mostra que a capacidade de endividamento da empresa é limitada pelo montante de capital empresarial. Mesmo no caso de uma empresa de capital aberto, Kalecki argumenta que a expansão do capital por meio da emissão de novas ações ordinárias também é restringida pelo tamanho do capital empresarial original. Portanto, em última instância, a expansão da empresa depende, fundamentalmente, da acumulação interna de capital; ou seja, da acumulação financiada a partir dos lucros brutos da empresa $^{14}$.

(13) É importante destacar, no entanto, que no livro Selected essays on the dynamics of the capitalist economy (1971), Kalecki desenvolveu uma versão modificada das teorias do crescimento com ciclos e das decisões de investimento.

(14) Assim, para Kalecki (1969, p. 91), "the variety in the size of enterprises in the same industry at a given time can be easily explained in terms of differences in entrepreneurial capital". Evidentemente que essa é uma explicação parcial, uma vez que não responde à questão de por que os montantes de capitais empresariais diferem entre as empresas de uma mesma indústria. Em outras palavras, a resposta de Kalecki apenas recoloca uma nova pergunta: por que algumas firmas possuem maior capital empresarial do que outras? Mas, de fato, Kalecki nem mesmo formula essa questão. 
Outro aspecto importante a se destacar em relação ao tamanho do capital empresarial se relaciona com o "risco crescente" associado com a expansão dos investimentos. Segundo Kalecki (1969, p. 92)

[a] firm considering expansion must face the fact that, given the amount of the entrepreneurial capital, the risk increases with the amount invested. The greater the investment in relation to the entrepreneurial capital, the greater is the reduction of the entrepreneur's income in the event of an unsuccessful business venture.

Portanto, o tamanho do capital empresarial também impõe limite aos investimentos por meio do princípio do "risco crescente".

Para Kalecki é importante deixar transparente a distinção entre investimento em capital fixo e em estoques, uma vez que os fatores que os determinam são diferentes. Vejamos, em primeiro lugar, a teoria dos determinantes do investimento em capital fixo, que se constitui no núcleo da sua teoria.

Kalecki faz uma distinção, que é fundamental na sua teoria de investimento, entre a decisão de investir e o investimento propriamente dito. Para ele, o importante é entender os fatores que determinam a decisão de investimento por parte das empresas. A decisão de investimento por período de tempo em capital fixo $\left(\mathrm{D}_{\mathrm{t}}\right)$ determina, no período posterior $t+\tau, \operatorname{com} \tau>0$, o investimento em capital fixo. Em termos matemáticos, Kalecki postula que

$$
\text { (1) } F_{t+\tau}=D_{t} \text {. }
$$

A seguir, Kalecki centra seus esforços na análise dos fatores que determinam a decisão de investir em capital fixo. Ele pressupõe, inicialmente, uma situação hipotética em que, no início do período em análise, não há novos planos rentáveis de investimento; ou seja, Kalecki supõe que todos os planos de investimento rentáveis já foram realizados e as empresas só realizarão novos investimentos se houver mudança na situação econômica. Em outras palavras, só haverá decisão de investir em novos bens de capital fixo se houver mudança na situação econômica que torne pelo menos um dos planos de investimento existente rentável. Kalecki considera três amplas categorias de mudanças na situação econômica que influenciariam as decisões de investir em capital fixo, quais sejam: (a) acumulação interna de capital; (b) variação nos lucros; e (c) variação no estoque de capital.

Em relação ao primeiro fator, o argumento de Kalecki, conforme foi visto acima, é que a expansão da empresa depende, fundamentalmente, da acumulação 
interna de capital ${ }^{15}$. Em outras palavras, a poupança bruta ${ }^{16}$ da empresa se constitui na principal fonte de financiamento dos novos investimentos. Assim, o montante total de poupança bruta corrente tende a ser utilizado na expansão do capital empresarial; isto é, a empresa tende a utilizar a poupança bruta no financiamento de novos investimentos. Kalecki também enfatiza que o aumento do capital empresarial que resulta da acumulação interna expande os limites tanto para a captação de recursos de terceiros no mercado de capital quanto para aquele que o princípio do "risco crescente" impõe a realização de novos investimentos. Portanto, o montante de poupança bruta corrente $\left(\mathrm{S}_{\mathrm{t}}\right)$ está diretamente relacionado com a taxa de decisões de investimento em capital fixo. Em termos de notação matemática, $D_{t}=f\left(S_{t}\right)$, sendo f' $>0$.

$\mathrm{O}$ aumento dos lucros por unidade de tempo $(\Delta \mathrm{P} / \Delta \mathrm{t})$ é o segundo fator considerado por Kalecki como tendo uma influência positiva sobre a decisão de investir em capital fixo. Se entre o início e o final do período em análise ocorrer uma elevação no montante de lucro da empresa, projetos de investimento, que eram considerados não rentáveis, podem, então, ser atrativos. Desta forma, Dt pode ser reescrito como $\mathrm{Dt}=\mathrm{g}(\Delta \mathrm{P} / \Delta \mathrm{t})$, sendo g' $>0$.

Finalmente, o aumento do estoque de capital fixo por unidade de tempo é considerado como tendo uma influência negativa sobre a decisão de investir. Supondo que o montante de lucro permaneça constante, um aumento do estoque de capital implica em uma redução da taxa de lucro e, portanto, impacta negativamente em $\mathrm{D}_{\mathrm{t}}$. Por isso, Kalecki postula que $\mathrm{D}_{\mathrm{t}}=\mathrm{z}\left(\Delta \mathrm{K}_{\mathrm{t}} / \Delta \mathrm{t}\right)$, sendo $\mathrm{z}^{\prime}<0$.

A partir destas considerações adicionais, Kalecki (1969: 98) conclui que:

the rate of investment decisions, $D$, is, as a first approximation, an increasing function of gross savings, $S$, and the rate of change in aggregate profits, $\Delta P / \Delta t$, and a decreasing function of the rate of change in the stock of capital equipment, $\Delta \mathrm{K} / \Delta \mathrm{t}$.

Logo, supondo que haja uma relação linear entre as variáveis acima explicitadas, a equação expressando a decisão de investimento em capital fixo $\left(\mathrm{D}_{\mathrm{t}}\right)$ pode ser escrita como segue:

(2) $\mathrm{D}_{\mathrm{t}}=\mathrm{a} \mathrm{S}_{\mathrm{t}}+\mathrm{b}\left(\Delta \mathrm{P}_{\mathrm{t}} / \Delta \mathrm{t}\right)-\mathrm{c}\left(\Delta \mathrm{K}_{\mathrm{t}} / \Delta \mathrm{t}\right)+\mathrm{d}$.

(15) Esse entendimento de Kalecki é corroborado pela evidência empírica tanto para os países capitalistas avançados quanto para o caso brasileiro. Segundo os dados apresentados por Coutinho (2010), as médias para o período 2001-2009 do padrão de financiamento dos investimentos na indústria e em infraestrutura foram as seguintes: lucros retidos $(49,3 \%)$, fundos captados junto ao BNDES (26,1\%), captações externas (10,7\%), debêntures $(8,1 \%)$ e emissão de novas ações $(5,9 \%)$.

(16) Para Kalecki, a poupança bruta corrente inclui os lucros não distribuídos, a depreciação e a "poupança pessoal” dos grupos controladores da empresa. Ou seja, a riqueza líquida à disposição dos capitalistas. 
em que: $\mathrm{S}_{\mathrm{t}}=$ poupança bruta corrente no período $\mathrm{t} ; \mathrm{P}_{\mathrm{t}}=$ lucro bruto agregado depois dos impostos deflacionados pelos preços dos bens de investimento no período $t ; K_{t}$ = estoque de capital fixo no período $\mathrm{t}$; e $\mathrm{d}_{\mathrm{t}}=$ constante que está sujeita a variações no longo prazo.

Combinando as equações (1) e (2), tem-se:

$$
\text { (3) } \mathrm{F}_{\mathrm{t}+\tau}=\mathrm{aS}_{\mathrm{t}}+\mathrm{b}\left(\Delta \mathrm{P}_{\mathrm{t}} / \Delta \mathrm{t}\right)-\mathrm{c}\left(\Delta \mathrm{K}_{\mathrm{t}} / \Delta \mathrm{t}\right)+\mathrm{d}_{\mathrm{t}} \text {. }
$$

Uma vez que $\Delta \mathrm{K}_{\mathrm{t}} / \Delta \mathrm{t}=\mathrm{F}_{\mathrm{t}}-\delta$ (sendo que $\delta$ representa a depreciação do estoque de capital), então, substituindo tal expressão na equação (3), obtém-se:

$$
\mathrm{F}_{\mathrm{t}+\tau}=\mathrm{aS}_{\mathrm{t}}+\mathrm{b}\left(\Delta \mathrm{P}_{\mathrm{t}} / \Delta \mathrm{t}\right)-\mathrm{c}\left(\mathrm{F}_{\mathrm{t}}-\delta\right)+\mathrm{d}_{\mathrm{t}}
$$

Dividindo a equação acima por $1 /(1+\mathrm{c})$ e rearranjando seus termos, tem-se:

$$
\left(\mathrm{F}_{\mathrm{t}+\tau}+\mathrm{c} \mathrm{F}_{\mathrm{t}}\right) /(1+\mathrm{c})=(\mathrm{a} / 1+\mathrm{c}) \mathrm{S}_{\mathrm{t}}+(\mathrm{b} / 1+\mathrm{c})\left(\Delta \mathrm{P}_{\mathrm{t}} / \Delta \mathrm{t}\right)+(\mathrm{c} \delta+\mathrm{d}) /(1+\mathrm{c}) .
$$

Como o lado esquerdo da equação acima é uma média ponderada de $\mathrm{F}_{\mathrm{t}+\tau} \mathrm{e}$ $F_{t}$, Kalecki supõe ser igual ao valor intermediário $F_{t+\theta}$, sendo $\theta$ um hiato temporal menor do que $\tau$. Reescrevendo, para simplificar, $b /(1+c)=b^{\prime}$ e $(c \delta+d) /(1+c)=$ $\mathrm{d}_{\mathrm{t}}$, logo a equação acima pode ser reescrita como:

$$
\text { (4) } \mathrm{F}_{\mathrm{t}+\theta}=\mathrm{a} /(1+\mathrm{c}) \mathrm{S}_{\mathrm{t}}+\mathrm{b}^{\prime}\left(\Delta \mathrm{P}_{\mathrm{t}} / \Delta \mathrm{t}\right)+\mathrm{d}_{\mathrm{t}}^{\prime} \text {, }
$$

sendo que d' é uma constante ainda que sujeita a variações de longo prazo, especialmente como consequência do progresso tecnológico e do crescimento populacional. Em relação ao valor de b' nada pode ser inferido a priori, bem como Kalecki supõe que $a /(1+c)<1$.

Finalmente, Kalecki argumenta que uma vez que $\mathrm{S}$ está relacionado com o nível da atividade econômica e que $\Delta \mathrm{P}_{\mathrm{t}} / \Delta \mathrm{t}$ está associado com a taxa de variação do nível da atividade econômica, a decisão de investimento em capital fixo, em última instância, é determinada (a) pelo nível da atividade econômica e (b) pela taxa de variação do nível da atividade econômica.

Vejamos, agora, a teoria dos determinantes do investimento em estoques. Segundo Kalecki, o "princípio do acelerador” se constitui em uma hipótese razoável para explicar as decisões de investir em estoques. Assim, ele propõe que

$$
\text { (5) } \mathrm{J}_{\mathrm{t}+\theta}=e\left(\Delta \mathrm{O}_{\mathrm{t}} / \Delta \mathrm{t}\right) \text {, }
$$

sendo $\mathrm{J}$ o montante de investimento em estoques e $\mathrm{O}$ o produto bruto real.

Finalmente, combinando as equações (4) e (5), Kalecki obtém a formula para o investimento total da economia:

$$
\text { (6) } \mathrm{I}_{\mathrm{t}+\theta}=\mathrm{a} /(1+\mathrm{c}) \mathrm{S}_{\mathrm{t}}+\mathrm{b}^{\prime}\left(\Delta \mathrm{P}_{\mathrm{t}} / \Delta \mathrm{t}\right)+e\left(\Delta \mathrm{O}_{\mathrm{t}} / \Delta \mathrm{t}\right)+\mathrm{d}_{\mathrm{t}}^{\prime} \text {. }
$$


Em outras palavras, o resultado obtido por Kalecki é que o investimento total depende tanto do nível da atividade econômica quanto da taxa de variação deste nível e a incorporação dos investimentos em estoques não altera fundamentalmente os determinantes do investimento total.

\subsubsection{Uma reformulação necessária: introduzindo as expectativas}

Na nossa opinião, o problema central da teoria desenvolvida por Kalecki está relacionado ao fato de não haver expectativas na equação do investimento. Vejamos isso de forma mais detalhada.

Em primeiro lugar, está claro que a variável poupança bruta das empresas (S) é igual aos lucros brutos dos capitalistas, uma vez que Kalecki supõe que os trabalhadores não poupam. Portanto, o que, de fato, está sendo considerado pela introdução desta variável é a influência dos lucros brutos sobre as decisões de investir. Assim, a relação entre a taxa de decisões de investimento em capital fixo $\left(D_{t}\right)$ e o montante de poupança bruta $\left(S_{t}\right)$ pode ser expressa como $D_{t}=f\left(P_{t}\right)$. Isso implica que a decisão de investimento depende diretamente do montante de lucro bruto no início do período em consideração e da variação desse montante ao longo desse período, ou seja: $\mathrm{D}_{\mathrm{t}}=\mathrm{f}_{1}\left(\mathrm{P}_{\mathrm{t}}, \Delta \mathrm{P}_{\mathrm{t}}\right)$.

No entanto, de acordo com Kalecki (1969: 54),

[p]rofits will thus be a function both of current investment and of investment in the near past; or, roughly speaking, profits follows investment with a time lag. We can thus write as an approximate equation: $\mathrm{P}_{\mathrm{t}}=\mathrm{f}\left(\mathrm{I}_{\mathrm{t}-\omega}\right)[\ldots]$, where $\omega$ is the time lag involved.

Evidentemente que esta relação de causalidade apresenta a seguinte questão: como é possível que o montante de lucros varie entre o início e o final do período em análise se, no início do período, o montante de investimento é supostamente constante? Parece-nos que a única reposta razoável, nesse contexto teórico, é supor que a variação considerada ocorra em relação aos lucros esperados (e não em supor que ocorra, no período em análise, uma variação efetiva dos lucros). Podemos, assim, reescrever a relação entre os fatores que influenciam diretamente as decisões de investir como:

$$
\text { (7) } D_{t}=f_{1}\left(P_{t}, \Delta P_{t}^{e}\right) \text {, }
$$

sendo que $\mathrm{P}_{\mathrm{t}}^{\mathrm{e}}$ representa o montante de lucro esperado para o período $\mathrm{t}$.

A incorporação das expectativas em relação aos lucros brutos implica na reformulação das equações (2) e (6) para

$$
\text { (2') } \mathrm{D}_{\mathrm{t}}=\mathrm{aS}_{\mathrm{t}}+\mathrm{b}\left(\Delta \mathrm{P}_{\mathrm{t}}^{\mathrm{e}} / \Delta \mathrm{t}\right)-\mathrm{c}\left(\Delta \mathrm{K}_{\mathrm{t}} / \Delta \mathrm{t}\right)+\mathrm{d}_{\mathrm{t}}
$$


(6') $\mathrm{I}_{\mathrm{t}+\theta}=(\mathrm{a} / 1+\mathrm{c}) \mathrm{P}_{\mathrm{t}}+\mathrm{b}^{\prime}\left(\Delta \mathrm{P}_{\mathrm{t}}^{\mathrm{e}} / \Delta \mathrm{t}\right)+e\left(\Delta \mathrm{O}_{\mathrm{t}} / \Delta \mathrm{t}\right)+\mathrm{d}^{\prime}{ }_{\mathrm{t}}$.

Com essa reformulação, as expectativas passam a ter um papel de grande relevância na explicação das decisões de investir e, portanto, na determinação das flutuações cíclicas do investimento. Deve-se também enfatizar que a introdução das expectativas em relação aos lucros brutos torna a teoria do investimento de Kalecki menos mecanicista ${ }^{17}$.

\subsubsection{A teoria do investimento em uma economia com crescimento econômico}

Para Kalecki, a explicação para a tendência de crescimento de longo prazo do nível do investimento e, por conseguinte, do produto, está associada, fundamentalmente, com os "fatores de desenvolvimento", que são captados, em última instância, por d'. Se o parâmetro específico que mede a intensidade desses fatores for positivo, então d' também apresentará uma tendência de crescimento de longo prazo. Assim, "[i]t may be concluded that in the absence of 'development factors' the system lapses into a stationary state” (Kalecki, 1969, p. 155). Portanto, a existência de uma tendência estável de crescimento de longo prazo depende de uma taxa constante de expansão das inovações. Se a intensidade dos fatores de desenvolvimento declinar no longo prazo isso determinará, por consequência, uma tendência de desaceleração da taxa de investimento e, portanto, do crescimento econômico ao longo do tempo. Na verdade, Kalecki supõe que o dinamismo econômico do capitalismo tende a declinar no tempo por consequência da tendência de declínio da intensidade das inovações.

Conforme vimos anteriormente, a decisão de investimento em capital fixo é determinada positivamente pela poupança bruta das empresas e pela taxa de aumento dos lucros, enquanto que o aumento do estoque de bens de capital impacta negativamente sobre a decisão de investir. Essa teoria é expressa pela equação (2) ou, mais apropriadamente, pela equação (2'). Além desses três determinantes, Kalecki também inclui a variável d que, por captar a influência dos "fatores de desenvolvimento" sobre as decisões de investimento, é considerada constante apenas no curto prazo, mas sujeita a variação no longo prazo. Por essa razão, esta variável é representada por $\mathrm{d}_{\mathrm{t}}$. Por sua vez, o desenvolvimento da teoria do investimento resulta na equação (6) ou, mais corretamente, na equação (6'). Nesses casos, a variável $\mathrm{d}_{\mathrm{t}}$ é substituída por $\mathrm{d}_{\mathrm{t}}=\left(\mathrm{c} \delta+\mathrm{d}_{\mathrm{t}}\right) /(1+\mathrm{c})$ que Kalecki também supõe ser constante no curto prazo, mas variável no longo prazo. A razão para esta hipótese é a seguinte: "[d]epreciation, $\delta$, fluctuates only very little in the course of the business cycle, but in the long run it varies in line with the volume of capital equipment

(17) Em trabalhos anteriores (por exemplo, Kalecki, 1970), Kalecki incorporou o papel das expectativas na análise do investimento. Todavia, foge ao escopo deste artigo desenvolver essa questão no contexto da teoria kaleckiana do investimento apresentada na presente subseção. 
(Kalecki, 1969, p. 104). Portanto, a variável d' continua expressando apenas os efeitos dos "fatores de desenvolvimento" sobre o nível de longo prazo do investimento.

Ademais, Kalecki considera três fatores importantes na determinação do nível de investimento no longo prazo, quais sejam: as inovações, a poupança dos rentistas e o crescimento populacional.

Em relação às inovações, que se constituem no fator fundamental da dinâmica de longo prazo, ele argumenta que, ao longo do período em análise, o surgimento delas afeta positivamente a decisão de investir, tendo um papel similar às variações dos lucros. Ou seja, uma taxa positiva de novas invenções durante o período em análise impacta diretamente as decisões de investimento. Cabe ressaltar que a concepção de inovações em Kalecki é bastante ampla, incluindo não apenas o desenvolvimento tecnológico, mas também a introdução de novos produtos e o acesso a novas fontes de matérias primas, desde que estes fatores requeiram a realização de investimentos em novos bens de capital fixo.

O outro fator apontado (poupança dos rentistas) é visto como afetando negativamente a taxa de crescimento de uma economia capitalista, enquanto o crescimento populacional pode reduzir os salários e estimular a acumulação.

Kalecki conclui sua análise afirmando que:

that long-run development is not inherent in the capitalist economy. Thus specific 'development factors' are required to sustain a long-run upward movement. Amongst such factors we singled out innovations in the broadest sense as the most important promoter of development. Another long run influence considered, rentier's savings, was found to be an obstacle rather than a stimulus to development (1969, p. 161).

\subsection{A institucionalidade do investimento na ótica de Keynes}

Como se sabe, o projeto de Keynes na The general theory of employment, interest and money (GT) consiste em, por um lado, mostrar a lógica de funcionamento de uma economia monetária, negando, assim, o princípio dos mercados autoequilibrantes e autorregulados, e, por outro lado, propor medidas econômicas que evitem as flutuações cíclicas dos níveis de produto e de emprego. Para Keynes, flutuações na demanda efetiva e no nível de emprego ocorrem porque, em um mundo no qual o futuro é incerto e desconhecido, os indivíduos preferem reter moeda e, por conseguinte, suas decisões de gastos, consumo e, principalmente, investimento, são postergadas.

Na GT, Keynes apresenta inúmeras passagens que deixam claro que o investimento é a variável determinante da renda e do emprego. A relevância do investimento para a teoria keynesiana é observada no princípio da demanda efetiva 
(PDE), em que flutuações na demanda e, portanto, nos níveis de emprego e renda, decorrem de alterações no investimento.

Quais são os fatores que influenciam o investimento? No capítulo 11 da GT, Keynes formaliza sua teoria do investimento tendo como referência a "eficiência marginal do capital" (EMgC), que diz respeito à taxa de desconto que iguala o fluxo de receitas esperadas (preço de demanda) ao custo do investimento (preço de oferta). Em outras palavras, a EMgC mostra o volume do investimento que se pode esperar para cada taxa de juros; portanto, para Keynes, o investimento é determinado pela igualdade entre a EMgC e o custo do capital. Nas palavras de Keynes (2007, p. 136):

the actual rate of current investment will be pushed to the point where there is no longer any class of capital-asset of which the marginal efficiency exceeds the current rate of interest.

Para Davidson (1994), a relação entre EMgC e o investimento (ou a quantidade máxima de bens de capital desejada pela firma) depende do preço de mercado, das expectativas de quase-renda, da taxa de juros e do número de firmas na economia. Analiticamente,

$$
\text { (8) } D_{I}=f\left(p_{I}, i, \alpha, \beta\right) \text {, }
$$

em que $\mathrm{p}_{\mathrm{I}}=$ preço de mercado, $\mathrm{i}=$ expectativas de quase-renda, $\alpha=$ taxa de juros e $\beta=$ número de firmas, sendo $\mathrm{f}_{\mathrm{pI}}<0, \mathrm{f}_{\mathrm{i}}>0, \mathrm{f}_{\alpha}<0$ e $\mathrm{f}_{\beta}>0$.

Retornando a Keynes, em um contexto de incerteza fundamental/radical, no qual não é possível se prever o futuro, a dinâmica econômica, ou demanda efetiva, é cíclica devido à instabilidade do investimento, uma vez que as expectativas que formam a $\mathrm{EMgC}$ são frágeis e têm como base tão somente convenções. Ademais, uma vez que a retenção de moeda, por parte dos indivíduos, se constitui em uma forma de segurança (hedge) contra a incerteza em relação aos seus planos de transações e produção, condicionando, assim, a dinâmica do processo produtivo, a instabilidade do investimento (renda e emprego) é recorrente.

Essas questões são apresentadas em dois capítulos específicos da GT: 12 e 17.

O capítulo 12 mostra que as tomadas de decisão de investimento, baseadas em expectativas frágeis sobre o comportamento futuro da demanda, o grau de confiança e as convenções, mais amplamente, instituições, são fundamentais para que o estado de ânimo (animal spirits) do empresário seja observado. Nas palavras de Keynes (2007, p. 161), parte substancial das tomadas de decisão "can only be taken as a result of animal spirits". Em outras palavras, o que condiciona favoravelmente o animal spirits e, portanto, o investimento, são as expectativas otimistas, naturezas política e social, instituições e política econômica, dentre outras variáveis. 
Por sua vez, no capítulo 17, Keynes (2007) mostra que a moeda é um ativo que se diferencia dos demais em razão de suas propriedades essenciais: por um lado, sua elasticidade de produção é zero - isto é, a moeda não é produzida pela quantidade de trabalho que o setor privado incorpora no processo produtivo; e, por outro lado, a elasticidade-substituição da moeda é nula, o que quer dizer que nenhum outro ativo não líquido exerce as funções de unidade de conta, meio de troca e reserva de valor que são desempenhadas pela moeda.

As referidas propriedades da moeda são fundamentais para caracterizar a importância que ela exerce em uma economia monetária: ao ser a segurança contra a incerteza, ela aproxima, por meio dos contratos monetários, passado, presente e futuro, coordenando, assim, a atividade econômica.

Pois bem, o PDE é desenvolvido a partir da ideia de não neutralidade monetária: existe insuficiência de demanda efetiva - e, portanto, de investimento pelo fato de que os indivíduos alocam renda na forma de riqueza não reprodutível, em vez de alocá-la para a aquisição de bens produzidos por trabalho. Assim, crises econômicas se manifestam porque a moeda é uma forma alternativa de riqueza.

É a partir desta ideia que a abordagem de Keynes é peculiar, pois a teoria keynesiana do investimento possui uma dinâmica própria, uma vez que o processo de financiamento do investimento, ou seja, o papel do crédito, conjuntamente com a decisão de investir dado o animal spirits do empreendedor, é fundamental para a sua realização. Essa relação investimento-crédito ficou conhecida como circuito financiamento-investimento-poupança-funding ${ }^{18}$.

A partir desta relação, o ponto principal de Keynes diz respeito às limitações da política monetária e da oferta de crédito em agir sobre a demanda por investimento. Tais limitações deviam-se à baixa elasticidade da $\mathrm{EMgC}$, à impossibilidade de se reduzir a taxa de juros (face à “armadilha da liquidez") e à preferência por liquidez do sistema financeiro, reduzindo, assim, a oferta de crédito. Enfim, a não realização do investimento geraria insuficiência de demanda efetiva e oscilações nos níveis de produto e logo na taxa de crescimento.

Diante deste contexto, qual é a solução de Keynes? Se a política monetária não consegue induzir os agentes econômicos a se livrarem da riqueza monetária, revertendo, assim, suas decisões de gastos (Keynes, 2007, p. 267), a intervenção do Estado, seja em termos de atividade produtiva e de políticas públicas, seja no sentido de criar mecanismos que propiciem um ambiente institucional favorável às tomadas de decisões dos agentes econômicos, constitui-se na solução para as crises de demanda efetiva.

(18) Para mais detalhes, ver Studart (1993). 


\section{3 À guisa de conclusão}

Pelo exposto nas subseções 2.1 e 2.1.1, economias capitalistas, nas visões kaleckiana e keynesiana, apresentam, inerentemente, problemas de insuficiência de demanda efetiva e, por conseguinte, flutuações cíclicas de renda e emprego devido à instabilidade do investimento. Este, por sua vez, combinando as duas concepções teóricas, está relacionado aos investimentos pretéritos (ou variação de estoques), aos lucros esperados pelos capitalistas, à taxa monetária de juros, volume de crédito e às expectativas favoráveis dos empresários - diga-se de passagem, esta é uma variável comum nas análises de Kalecki e Keynes. Pois bem, estabelecida, a partir de nosso referencial teórico, uma relação causal entre investimento e as referidas variáveis, a seção seguinte objetiva mostrar empiricamente como esta relação de causalidade é observada na economia brasileira, visando, com isso, compreender por que a taxa média de crescimento do PIB, no período pós-PR, foi relativamente baixa, a despeito da estabilização monetária obtida desde então.

\section{A dinâmica do investimento no Brasil: uma análise empírica}

Nesta seção são examinados empiricamente a evolução do investimento e os possíveis determinantes sugeridos pela seção anterior. Nesse sentido, a análise empírica é feita primeiramente por meio de ilustrações descritivas, sem ser exaustiva em termos dos determinantes, e em seguida por meio de modelos econométricos de vetor de correção de erros para aprofundar o entendimento dos determinantes do investimento. Cabe o caveat de que trabalhar com dados para a economia brasileira é sempre um desafio, em função das frequentes mudanças de metodologia, bases de comparação distintas, incompletude e descontinuidade das séries ${ }^{19}$. Esta limitação deve ser considerada ao avaliar a significância e robustez dos testes efetuados; isto é particularmente importante no caso de variáveis empregadas para aprofundar quantitativamente as abordagens de Kalecki e Keynes, que são complexas e não facilmente reproduzíveis mesmo para bases de dados mais fidedignas. Por exemplo, as defasagens temporais discutidas por Kalecki em sua teoria não são fixas nem determinadas, ainda que em suas aplicações estatísticas elas variem entre um ano e um trimestre, e isto impõe uma dificuldade no tratamento estatístico do seu modelo para os dados do Brasil. Além disso, mesmo para as séries com informações para todo o período, um lapso de 20 anos pode ser relativamente curto em função das mudanças na metodologia de coleta de dados e dos possíveis ruídos nas séries.

(19) Para uma discussão específica sobre os dados de investimento no Brasil, consultar Santos et al. (2015). 


\subsection{Análise empírica descritiva}

O Gráfico 1 abaixo apresenta a taxa de crescimento real da FBKF como ilustração para a discussão efetuada na seção 1 acima. A contribuição da FBKF para o crescimento do PIB em pontos percentuais também é apresentada, mostrando comportamento idêntico ao crescimento real da FBKF. Como seria de se esperar com base na discussão da seção 2 , o crescimento do investimento excluindo variações de estoques apresenta flutuações de curto e de longo prazo. Há uma tendência de declínio até 2003, uma retomada do crescimento real até 2008 e novo declínio desde então, com forte queda durante a crise financeira global e forte expansão cíclica em 2010 .

A evolução do índice real (preços de 1980) dos dois principais componentes do investimento no período é apresentada no Gráfico 2, com uma forte expansão do investimento em máquinas e equipamentos a partir de 2003, e do investimento em construção no mesmo período. A queda reduzida no investimento em construção sugere efeitos positivos das políticas anticíclicas, principalmente do PAC.

\section{Gráfico 1}

Taxa de crescimento real da FBKF (eixo esquerdo) e Contribuição da FBKF para o crescimento do PIB (eixo direito) no Brasil (\% a.a.): 1994-2013 (Referência 2000)

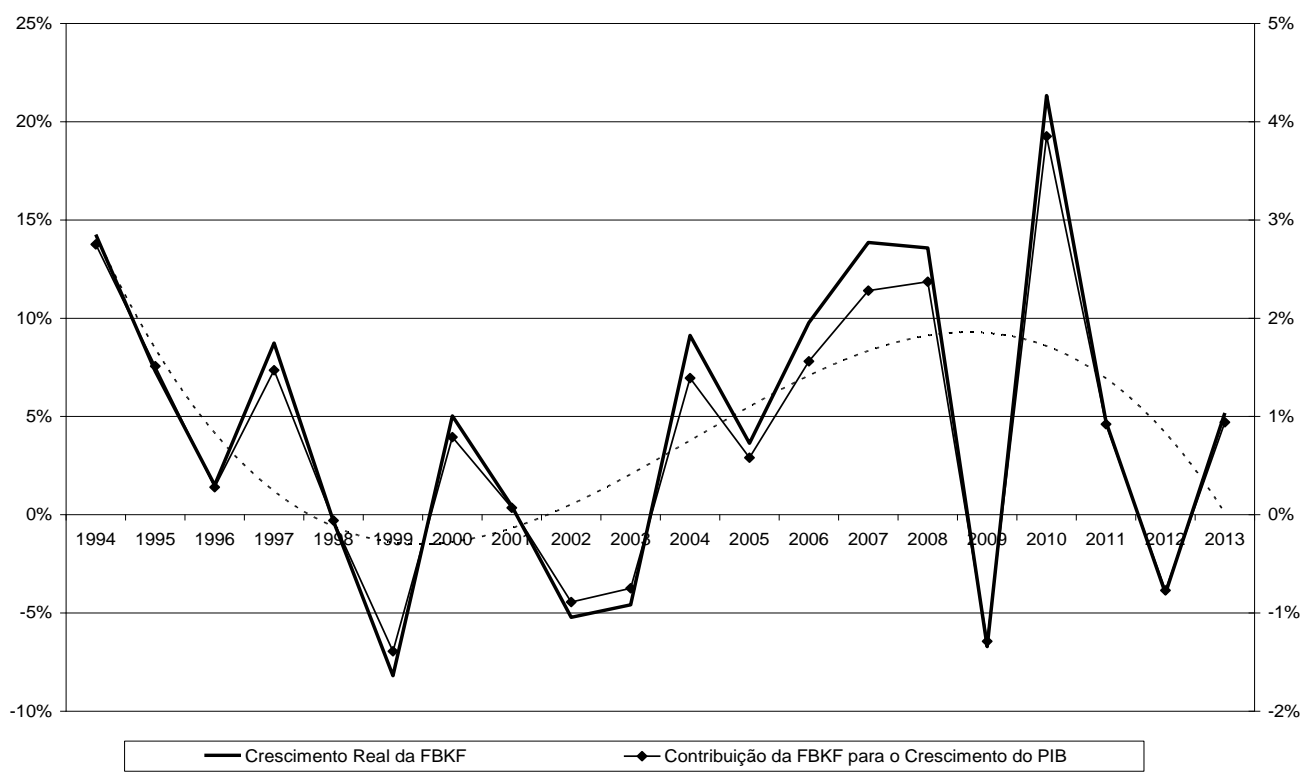

Nota: A linha pontilhada representa o polinômio de melhor ajuste para o crescimento da FBKF (terceiro grau).

Fonte: Elaborado pelos autores com dados do Ipeadata (2015) (não há informação sobre o ano-base para deflacionar as taxas nominais de crescimento). 
Gráfico 2

Índice dos principais componentes da FBKF no Brasil $(1994-2013)(1980=100)$

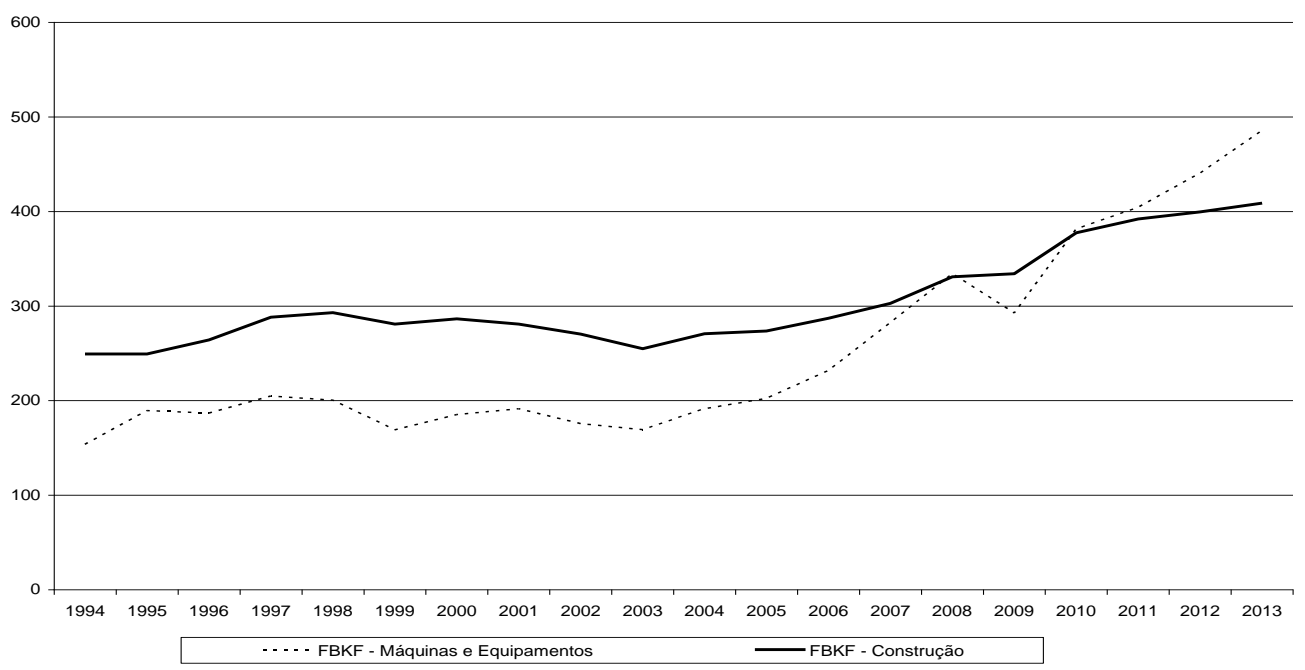

Fonte: Elaborado pelos autores com dados do Ipeadata (2015).

Gráfico 3

Taxas de crescimentos reais do PIB (eixo direito) e do investimento (eixo esquerdo) e relação FBKF/PIB (eixo esquerdo) no Brasil (1994-2013)

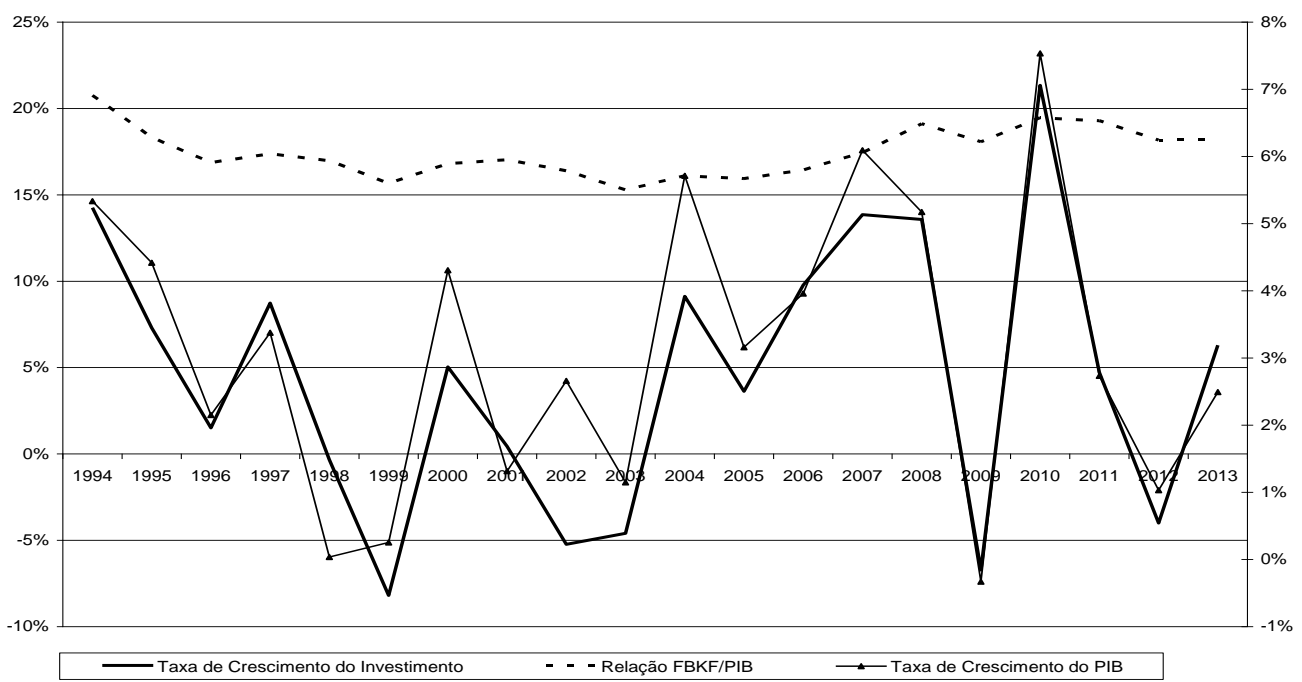

Fonte: Elaborado pelos autores com dados do Ipeadata (2015).

No Gráfico 3 é ilustrada a evolução da relação FBKF/PIB e a forte correlação positiva entre o crescimento do PIB real e o crescimento do investimento real, principalmente depois da crise global. Esta relação já havia sido sugerida no Gráfico 1 pela contribuição do crescimento do investimento para o crescimento do produto. A forte relação entre as taxas de crescimento explica a relativa constância da taxa de 
investimento. A relação investimento/PIB flutua entre $15,3 \%$ e $20,7 \%$, com uma tendência de declínio gradual até 2003 e leve crescimento a partir de então, estagnando depois da crise global e com tendência de queda após 2011. Como discutido na seção anterior, na equação final do investimento de Kalecki fica clara a relação entre investimento e PIB, ainda que com defasagens. Na teoria keynesiana, o produto depende da demanda efetiva, sendo o investimento o componente mais importante. A relação das variáveis em níveis sugere uma relação também em termos das taxas de crescimento.

A relação entre a FBKF real, o saldo de crédito ao setor privado como percentual do PIB e a taxa real anual média de juros (SELIC) pode ser vista no Gráfico 4. Há uma fortíssima relação entre a razão crédito/PIB e o investimento real, como esperado pela teoria keynesiana. Com relação à taxa real de juros, até 2003, a forte queda na mesma não havia afetado o nível de investimento real. A partir de então, há uma clara relação inversa entre as duas variáveis.

Por fim, o Gráfico 5 mostra a relação entre a FBKF real e o Índice de Confiança do Empresário Industrial (ICEI) da Confederação nacional da Indústria (CNI), proxy para expectativas. Pelo referido Índice, valores acima de 50 mostram otimismo, e vice-versa. A série é relativamente constante, com os empresários otimistas durante todo o período, com redução do Índice ao final do período, mas sem impacto sobre o investimento real.

\section{Gráfico 4}

FBKF (eixo esquerdo) em R \$ milhões de 2013, crédito ao setor privado como \% do PIB (eixo direito) e Taxa SELIC (eixo direito) no Brasil (1994-2013)

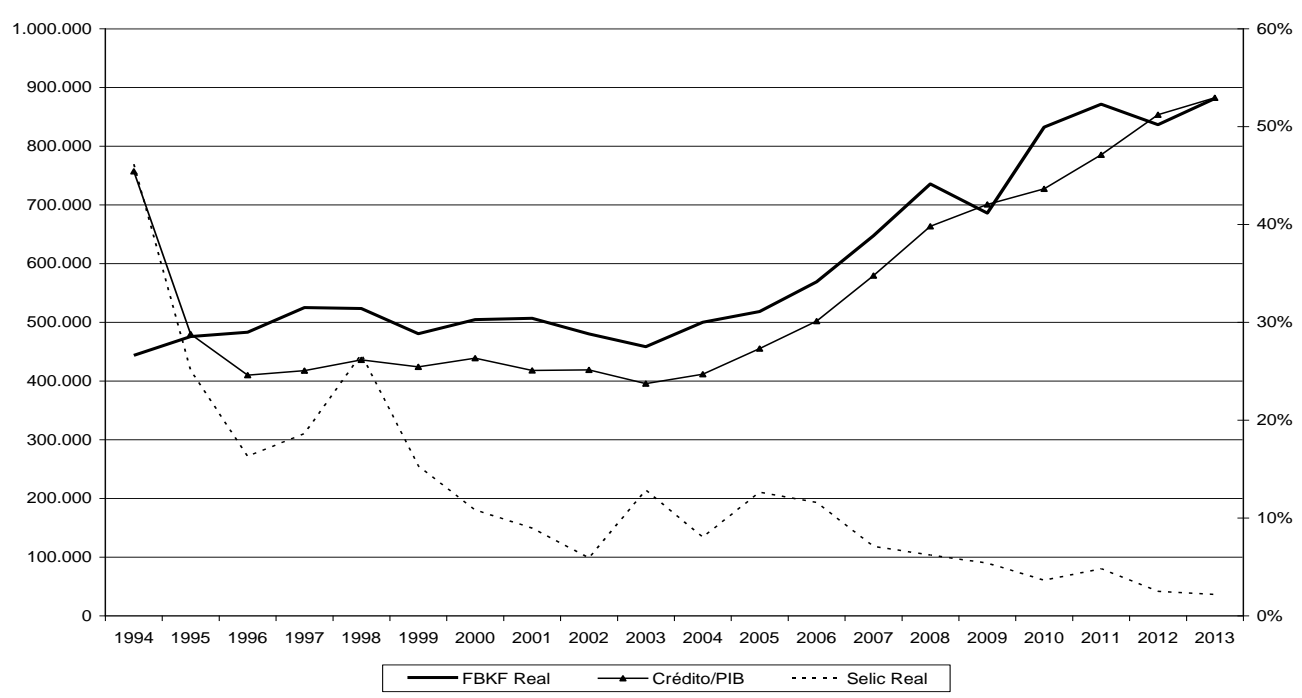

Fonte: Elaborado pelos autores com base nos dados do Ipeadata (2015) e do BCB (2015). 
Gráfico 5

FBKF (eixo esquerdo) em R \$ milhões de 2013 e ICEI-Expectativas (CNI) (1994-2013)

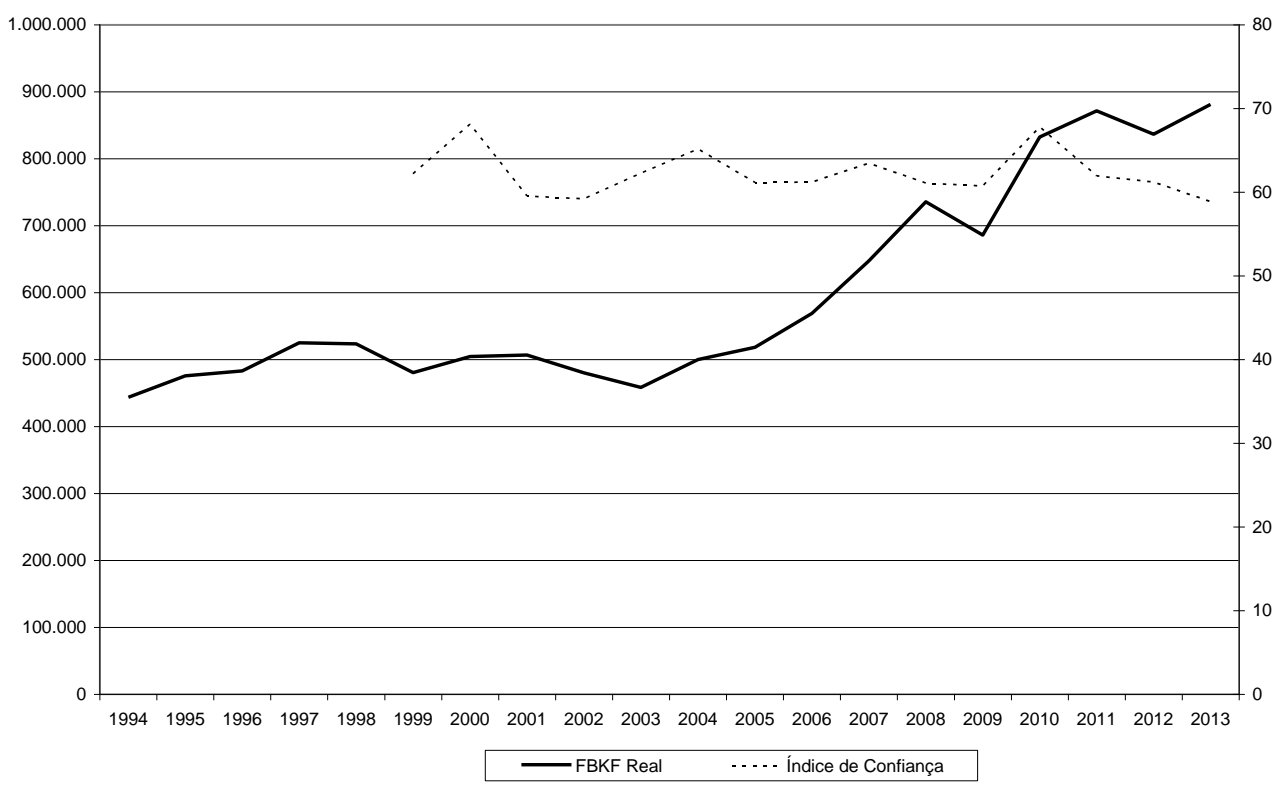

Fonte: Elaborado pelos autores com base no Ipeadata (2015).

\subsection{Análise econométrica}

A literatura econométrica sobre modelos baseados nos textos originais de Kalecki e Keynes é exígua, dado os problemas associados à coleta de dados fieis às teorias apontadas acima. Um texto que busca estimar estas relações é o de Baddeley (2003). A autora compara o modelo convencional tipo $Q$ de Tobin com um modelo keynesiano-kaleckiano (ou pós-Keynesiano), de maneira a enfatizar o papel da incerteza e fatores cíclicos. No modelo estimado de Tobin, o investimento depende dos valores correntes e defasados do estoque de capital, Q de Tobin, do preço dos bens de capital, da utilização da capacidade, da volatilidade do preço dos bens de capital e do volume de negócios da bolsa de valores. No modelo keynesianokaleckiano o investimento depende dos valores correntes e defasados do crescimento dos lucros, do crescimento do estoque de capital, da poupança empresarial, de uma tendência temporal, da utilização da capacidade, da volatilidade do preço dos bens de capital e do volume de negócios da bolsa de valores. Foram utilizados dados anuais da economia norte-americana para o período 1970-1998, um horizonte curto considerando-se a quantidade de parâmetros estimados.

A estratégia adotada neste trabalho é distinta: são estimados dois modelos para cada teoria, considerando diferentes elementos teóricos, e se introduz apenas 
um reduzido número de variáveis explicativas ${ }^{20}$. O objetivo destas diferentes especificações é proporcionar uma maior aderência à discussão teórica da seção anterior, mas com ajustes impostos pela disponibilidade de dados. Para a teoria kaleckiana, o primeiro modelo linear inclui a $\mathrm{FBKF}^{21}$ real (deflacionada pelo índice de preços de bens de capital), o PIB real (que inclui a FBKF) e a variação do PIB real para o período 1994-2013, ao passo que o segundo modelo, também linear, inclui a FBKF real, o estoque de M4 real como aproximação bastante imperfeita para o estoque de "poupança" bruta dos capitalistas (este agregado inclui também a poupança bruta dos rentistas, que para Kalecki reduz o investimento), o estoque de capital real e o lucro (excedente operacional bruto) real para o período 1990-200822. O problema com as especificações inspiradas na obra de Kalecki é que a teoria combina variáveis em níveis e taxas de variação, e as últimas tendem a se comportar como processos estacionários, potencialmente alterando a ordem de integração das variáveis no modelo, além de poderem assumir valores negativos, impossibilitando transformações logarítmicas dos dados, o que afeta o valor dos coeficientes, como fica claro a seguir. Variáveis importantes e tradicionalmente inseridas nos modelos neokaleckianos, como a utilização da capacidade, foram deixadas de fora para simplificar a discussão, assim como indicadores de política fiscal (déficit e dívida), taxa de câmbio e fluxos de capitais. Depreciação e expectativas também não foram tratadas, assim como aspectos autorregressivos da FBKF.

Para as versões keynesianas, foram estimados primeiramente um modelo linear baseado na formulação de Davidson, com a FBKF real, o índice de preços do estoque de capital, ICEI da CNI como aproximação para as expectativas de quaserendas $^{23}$, a taxa real de juros de curto prazo (SELIC) e o número de firmas ${ }^{24}$, sendo o modelo estimado para o período 1999-2013. Um segundo modelo linear, para o

(20) Um outro estudo sobre os determinantes do investimento no Brasil, mas voltado para o investimento privado no período 1970-2005, com outra metodologia econométrica, pode ser consultado em Luporini e Alves (2010).

(21) Não se separa neste estudo a FBKF entre construção residencial e construção comercial e infraestrutura, o que permitirá isolar as decisões de acumulação dos capitalistas. Para um estudo detalhado segregando o investimento por setores, ver Bielschowsky et al. (2015).

(22) O intervalo foi estendido até 1990 para compensar a falta de dados para o período recente. A inclusão do período pré-redução da inflação pode afetar a interpretação dos resultados, principalmente se prevalecer a hipótese da visão convencional de que uma inflação baixa e estável é condição necessária para investir e crescer de forma sustentável. Os valores do estoque de M4 e dos lucros foram ajustados com base no IGP-DI do ano 2000, a FBKF foi corrigida pelo deflator dos preços dos bens de capital e o valor real do estoque de capital para os preços do ano 2000 é obtido diretamente pelo Ipeadata (2015).

(23) O Ipeadata disponibiliza o ICEI-CNI com dados desde 1999, o que aumenta as dificuldades de estimação pela redução dos graus de liberdade. Além disso, esta construção torna a variável estacionária, pois flutua ao redor de um ponto de referência (50). De qualquer forma, não está claro em que medida este tipo de indicador capta as expectativas conforme teorizadas por Keynes, uma vez que a incerteza radical keynesiana não pode ser mensurada.

(24) Dados do Cempre-IBGE. É importante ressaltar que houve uma mudança na metodologia de coleta de dados em 2006, mas nenhum ajuste foi efetuado neste trabalho. 
período 1994-2013, inclui a FBKF real, o PIB real como aproximação para o nível de atividade econômica de curto prazo (que pode convencionalmente ser projetado para o futuro como indicador do estado de atividade econômica), a taxa real de juros e a relação crédito ao setor privado/PIB como forma de incorporar o momento inicial proposto pela teoria do circuito finance-investimento-poupança-funding. Assim como no caso kaleckiano, apesar das diferenças em termos de dinâmica, as determinações institucionais do investimento na visão keynesiana são mais difíceis de se mensurar e não foram tratadas neste trabalho. Além disso, o agregado M4, se fosse incorporado no modelo keynesiano, poderia reduzir o investimento ao possivelmente aproximar a preferência pela liquidez.

A análise econométrica das séries de tempo passa pela identificação da estacionariedade das séries. A inspeção visual dos gráficos acima sugere que as variáveis selecionadas, com exceção das expectativas, não são estacionárias e possuem raiz unitária, ou são estacionárias ao redor de uma tendência temporal determinística. Foram feitos testes de raiz unitária DF-GLS (Dickey-Fuller teste com ajuste dos dados) das variáveis em níveis e com uma defasagem, incluindo e excluindo uma tendência linear. O número de defasagens utilizadas nos testes foi sugerido pelo critério AIC modificado de Ng-Perron (MAIC). O Quadro 1, em anexo, resume os resultados. As variáveis utilizadas nas versões kaleckianas são não estacionárias em todas as especificações, sendo preciso estimar vetores de correção de erros. Para o primeiro modelo keynesiano, apenas a variável de aproximação das expectativas é estacionária. As demais variáveis possuem raiz unitária nos dois tipos de teste empregados. Como o número de observações é reduzido para trabalhar com diferenças para as variáveis com tendência, após os testes decidiu-se excluir a variável ICEI-CNI da estimação. No segundo modelo, todas as variáveis têm raiz unitária, com ou sem defasagem.

Em seguida foram determinadas as defasagens necessárias para determinar a quantidade de vetores cointegrados, com base nas estatísticas AIC, SBIC, HQIC e LR. Para o primeiro modelo kaleckiano, com uma defasagem para o PIB real e para o crescimento do PIB real, os testes estatísticos sugerem o emprego de três defasagens. A inclusão do investimento defasado como variável explicativa não produziu resultados significativos. Para o segundo modelo, com a variação no estoque real de capital e nos lucros reais e o estoque de M4, os testes sugerem quatro defasagens, mas este número inviabiliza determinar o número de equações de cointegração. Foram empregadas três defasagens. Para os dois modelos keynesianos, os testes sugerem quatro defasagens. Contudo, o número de defasagens necessárias para a existência de relações estacionárias de longo prazo não foram sempre as sugeridas pelo teste.

O próximo passo envolve a análise de cointegração. A especificação das equações foi escolhida com base na existência de pelo menos uma relação de 
cointegração e aproximação com o modelo teórico. Usando a metodologia de Johansen (1995), a inclusão de tendência temporal no diagnóstico sugere a não existência de cointegração. Apenas uma constante não restrita foi incluída. Para o primeiro modelo kaleckiano a estatística traço sugere, ao nível de 5\%, a existência de uma combinação linear cointegrada. Para o segundo, são sugeridas três possíveis combinações lineares estacionárias ao mesmo nível. Para o primeiro modelo keynesiano sem expectativas, há três combinações a 5\%. Para o segundo modelo, não há relação de cointegração para quatro defasagens. Para três defasagens há duas relações de cointegração a 5\%.

Finalmente, procede-se à estimação dos vetores de correção de erros $(\mathrm{VEC})^{25}$. Considerou-se abaixo apenas o vetor cointegrado para a relação de longo prazo, não os coeficientes que medem os ajustes de curto prazo para reestabelecer o "equilíbrio" quando a relação entre as variáveis é perturbada por choques aleatórios. Todos os coeficientes da equação de cointegração para os quatro modelos foram estatisticamente significativos. No primeiro modelo kaleckiano, o elevado coeficiente para o crescimento real defasado se explica pela característica do modelo, de incluir variáveis em níveis e taxas de crescimento. O sinal do crescimento defasado do PIB não foi o esperado, sugerindo que no longo prazo estas duas variáveis se ajustam em direções opostas. Por sua vez, o segundo modelo teve todos os sinais como previsto na teoria:

Modelo 1: FBKF real - 0,36 PIB real $-1+6.667 .116$ Crescimento do PIB real $_{-1}+$ $16.133 \mathrm{~T}+538.509=\varepsilon$;

Modelo 2: FBKF real - 0,66 M4 real - 1,16 $\Delta$.Lucro real + 3,38 $\Delta$.Estoque de Capital real $+12.081 \mathrm{~T}-182.774=\varepsilon$

No primeiro modelo keynesiano, a inclusão de quatro ou três defasagens exibiu coeficientes sem significância estatística, embora as variáveis possuíssem os sinais esperados. $\mathrm{O}$ vetor foi estimado com duas defasagens apenas. $\mathrm{O}$ coeficiente para o número de firmas não tem o sinal esperado, e o elevado coeficiente para a taxa real de juros, que tem o sinal esperado, se explica pelos problemas discutidos para o primeiro modelo kaleckiano. O segundo modelo apresentou a relação crédito ao setor privado/PIB com o sinal invertido, o que é surpreendente dada a relação exposta no Gráfico 4 acima. As demais variáveis apresentaram o sinal esperado. Os coeficientes elevados são explicados pelas razões expostas acima.

(25) Cabe notar que o modelo supõe uma relação de equilíbrio de longo prazo (cointegração) entre as variáveis não estacionárias, havendo correções ou ajustes da trajetória das variáveis no curto prazo. A discussão sobre em que medida este conceito tradicional de equilíbrio e processo de ajuste pode ser aplicado de forma coerente à teoria de Keynes e de Kalecki está além do escopo deste trabalho. 
Modelo 1: FBKF real - 261 Deflator dos Preços dos Bens de Capital + 1.498.283 Taxa real de juros $+0,015$ Número de firmas $-662.098=\varepsilon$;

Modelo 2: FBKF real $-4,02$ PIB real +1.917 .420 Taxa real de juros +9.461 .916$ [Crédito para o setor privado/PIB] $-333.548 \mathrm{~T}+8.151 .381=\varepsilon$

\subsection{Discussão}

A avaliação dos quatro modelos estimados indica que os mesmos não se mostraram robustos a diferentes especificações de tendência e defasagem, e nem sempre os sinais foram os esperados pela teoria. Apesar disso, os modelos estimados relevam algumas características relevantes para o entendimento da economia brasileira. Em primeiro lugar, o primeiro modelo kaleckiano mostra que os níveis de atividade econômica são mais importantes que as variações deste nível para os gastos de investimento no longo prazo. Isso é reforçado pelo segundo modelo keynesiano. O segundo modelo kaleckiano, embora estimado para um período distinto, se mostrou o mais aderente aos dados. Os lucros e o estoque de riqueza líquida variam de forma proporcional aos investimentos no longo prazo, enquanto o estoque de capital se move em direção contrária. Isto está de acordo com a discussão sobre fontes de financiamento na nota de rodapé 15. Em ambos os modelos keynesianos a taxa de juros se move em direção contrária à FBKF no longo prazo. Já o preço dos bens de capital se move na mesma direção da FBKF, ao contrário do sugerido por Davidson (sendo o preço um fator de custo para quem investe).

Ainda segundo a visão keynesiana, o número de empresas não se move na mesma direção da FBKF, assim como a relação crédito ao setor privado como proporção do PIB. Este último foi o resultado mais surpreendente. A inspeção visual gráfica mostra uma forte correlação positiva entre as variáveis. Uma possível explicação é que, no "equilíbrio" de longo prazo, seria preciso ter informações sobre o funding do investimento. A expansão do crédito ou finance pode elevar o investimento no curto prazo, mas o processo se torna insustentável sem financiamento de longo prazo. Por outro lado, as taxas de juros de curto prazo se movem em direção contrária aos investimentos e podem compensar o movimento conjunto de investimento e expansão do crédito ao setor privado. A existência de uma associação positiva entre investimento e estoque de riqueza líquida no modelo kaleckiano pode apontar na mesma direção: a riqueza líquida, com grande participação de títulos públicos de longo prazo e títulos privados de curto e curtíssimo prazo, poderia ampliar o volume de investimento no curto prazo pela transformação de lucros em dinheiro antes da conversão em capital fixo novamente, mas é preciso um mercado de títulos privados mais robusto de longo prazo para garantir este último estágio, sem indexação às taxas de juros de curto prazo. 
Em suma, a escassez de dados para um período mais longo e de variáveis que captem os aspectos centrais das teorias do investimento, como as expectativas, impede um tratamento dinâmico mais adequado aos determinantes do investimento. Pesquisas adicionais são necessárias para melhor mensurar e desenvolver as variáveis de forma coerente com a teoria do investimento. Mesmo com estas limitações, outros testes estatísticos poderiam iluminar diferentes dimensões desta pesquisa e mostrar os principais impedimentos ao crescimento dinâmico e sustentável da economia brasileira. Outra possibilidade seria combinar elementos das duas versões, kaleckiana e keynesiana, em uma única equação, como Baddeley (2003).

\section{Considerações finais}

$\mathrm{O}$ artigo apresentou fundamentos teóricos e evidências empíricas para interpretar o fraco desempenho da economia brasileira nos últimos 20 anos. Em resumo, o resultado pode ser explicado pelo comportamento do investimento agregado e seus determinantes. Os problemas macroeconômicos dos anos 1980 levaram a uma reação neoliberal nos anos 1990, sem qualquer efeito substancial sobre o investimento e o crescimento até 2003. Apenas durante um breve interregnum nos anos 2000 houve uma retomada da acumulação de capital, mas ainda em bases incipientes e insustentáveis.

Os resultados econométricos auxiliam na conclusão de que o crescimento volátil e tendencialmente pouco dinâmico do Brasil nos últimos 20 anos pode ser explicado por um investimento volátil e que não se sustenta em níveis elevados. Os estímulos proporcionados por um maior nível de atividade econômica à la efeito acelerador, via consumo doméstico, gasto público ou exportação de commodities, por exemplo, são importantes, mas parecem insuficientes para sustentar a expansão da acumulação de capital, que por sua vez acaba por se refletir em níveis reduzidos de atividade econômica via demanda efetiva, já que as duas se movem na mesma direção no longo prazo. Isto exige avaliar econometricamente os outros determinantes do investimento. Os resultados encontrados sugerem que as elevadas taxas reais de juros de curto prazo no Brasil, ainda que em trajetória de queda, são uma possível restrição à expansão sustentada da acumulação, principalmente quando se tornam referência para as taxas de longo prazo. O estoque de riqueza líquida se coloca como impulso ao investimento mas, surpreendentemente, a expansão do crédito ao setor privado não se move na mesma direção do investimento no VEC estimado. De qualquer forma, há limites para a expansão desta como propulsora da FBKF na ausência de um mercado de títulos privados de longo prazo. Problemas de funding podem explicar os problemas da acumulação de capital e do crescimento no Brasil. 
Por outro lado, a distribuição de renda em favor do trabalho nos últimos 12 anos pode estimular o investimento via aumentos do consumo e da produção, mas afetam os lucros, que movem a acumulação de capital em uma economia capitalista por ser a principal fonte de financiamento. Assim, o estoque de capital, resultado de decisões pretéritas de investimento, se apresenta como um elemento limitador da FBKF, na medida em que, se os lucros não crescem na mesma velocidade que o estoque de capital, a taxa de lucro se reduz. Esta se apresenta como uma contradição inerente às economias capitalistas. Porém, a experiência histórica brasileira sugere que há espaço para políticas de estímulo à acumulação, por meio da criação de um ambiente institucional favorável.

\section{Referências bibliográficas}

BADDELEY, M. Investment - theories and analysis. London: Palgrave MacMillan, 2003.

BANCO CENTRAL DO BRASIL (BCB). Séries temporais. Disponível em: http://www.bcb.gov.br. Acesso em: 20 mar. 2015.

BARBOSA FILHO, N. Latin America: counter-cyclical policy in Brazil: 2008-09. Journal of Globalization and Development, v. 1, n. 1, p. 1-12, Jan. 2010.

BIELSCHOWSKY, R.; SQUEFF, G.; VASCONCELOS, L. F. Evolução dos investimentos nas três frentes de expansão da economia brasileira na década de 2000. Brasília: Ipea, 2015. (Texto para Discussão, n. 2063).

COUTINHO, L. A construção de fundamentos para o crescimento sustentável da economia brasileira. In: ALÉM, A. C.; GIAMBIAGI, F. (Org.). O BNDES em um Brasil em transição. Rio de Janeiro: BNDES, 2010.

DAVIDSON, P. Post Keynesian macroeconomic theory: a foundation successful economic policies for the Twenty-First century. Aldershot: Edward Elgar, 1994.

FERRARI FILHO, F.; PAULA, L.F.R. The legacy of the Real Plan and an alternative agenda for the Brazilian economy. Investigación Económica, v. LXII, n. 244, p. 57-92, abr./jun. 2003.

IBGE. Indicadores. Disponível em: http://www.ibge.gov.br. Acesso em: 20 mar. 2015.

IMF. Data and statistics. Disponível em: http://www.imf.org. Acesso em: 10 mar. 2015.

IPEADATA. Macroeconômico. Disponível em: http://www.ipeadata.gov.br. Acesso em: 20 mar. 2015. 
JOHANSEN, S. Likelihood-based inference in cointegrated vector autoregressive models. Oxford: Oxford University Press, 1995.

KALECKI, M. Theory of economic dynamics: an essay on cyclical and long-run changes in capitalist economy. $2^{\text {nd }}$. ed. New York: Augustus M. Kelley Publishers, 1969.

KALECKI, M. Estudios sobre la teoría de los ciclos económicos. Barcelona: Ediciones Ariel, 1970.

KALECKI, M. Selected essays on the dynamics of the capitalist economy (19331970). Cambridge: Cambridge University Press, 1971.

KEYNES, J. M. The general theory of employment, interest and money. London: Palgrave Macmillan, 2007.

LUPORINI, V.; ALVES, J. Investimento privado: uma análise empírica para o Brasil. Economia e Sociedade, Campinas, v.19, n. 3, p. 449-475, dez. 2010.

NASSIF, A. Há evidências de desindustrialização no Brasil? Revista de Economia Política, v. 28, n. 1 (109), p. 72-96, jan./mar. 2008.

OREIRO, J. L. C.; FEIJÓ, C. Desindustrialização: conceituação, causas, efeitos e o caso brasileiro. Revista de Economia Política, v. 30, n. 2 (118), p. 219-232, abr./jun. 2010.

SANTOS, C. H. M.; MODENESI, A. M.; SQUEFF, G.; VASCONCELOS, L.; MORA, M.; FERNANDES, T.; MORAESS, T.; SUMMA, R.; BRAGA, J. Revisitando a dinâmica trimestral do investimento no Brasil: 1996-2012. Rio de Janeiro: IE-UFRJ, 2015. (Texto para Discussão, n. 5).

STUDART, R. O sistema financeiro e o financiamento do crescimento: uma alternativa pós-keynesiana à visão convencional. Revista de Economia Política, v. 13, n. 1, (49), p. 101-118, jan./mar. 1993. 


\section{Anexo}

Quadro 1

Testes de estacionariedade*

\begin{tabular}{|c|c|c|c|}
\hline Variável (período) & $\begin{array}{l}\text { DF-GLS com tendência } \\
\text { linear } \\
\text { (número de defasagens) }\end{array}$ & $\begin{array}{c}\text { DF-GLS sem tendência } \\
\text { linear (número de } \\
\text { defasagens) }\end{array}$ & Estacionária? \\
\hline FBKF real (94-13) & Não rejeita H0 a 10\% (1) & Não rejeita H0 a 10\% (1) & Não \\
\hline FBFK real-1 $(95-13)$ & Não rejeita H0 a 10\% (1) & Não rejeita H0 a 10\% (1) & Não \\
\hline PIB real (94-13) & Não rejeita $\mathrm{H} 0$ a $10 \%$ (1) & Não rejeita H0 a 10\% (2) & Não \\
\hline PIB real-1 $(95-13)$ & Não rejeita H0 a 10\% (1) & Não rejeita H0 a 10\% (3) & Não \\
\hline $\begin{array}{l}\text { Crescimento PIB real } \\
(95-13)\end{array}$ & Não rejeita H0 a 10\% (3) & Não rejeita H0 a 10\% (3) & Não \\
\hline $\begin{array}{l}\text { Crescimento PIB real-1 } \\
(96-13)\end{array}$ & Não rejeita H0 a $10 \%$ (3) & Não rejeita H0 a 10\% (3) & Não \\
\hline FBKF real $2000(90-08)$ & Não rejeita H0 a $10 \%$ (1) & Não rejeita H0 a 10\% (6) & Não \\
\hline $\begin{array}{l}\text { Estoque KF real } 2000 \\
(90-08)\end{array}$ & Não rejeita H0 a 10\% (1) & Não rejeita H0 a 10\% (1) & Não \\
\hline $\begin{array}{l}\Delta . \text { Estoque KF real } 2000 \\
(90-08)\end{array}$ & Não rejeita H0 a 10\% (1) & Não rejeita H0 a 10\% (7) & Não \\
\hline Lucros 2000 (90-08) & Não rejeita H0 a $10 \%$ (1) & Não rejeita H0 a $10 \%$ (1) & Não \\
\hline$\Delta$. Lucros $2000(90-08)$ & Não rejeita H0 a 10\% (1) & Não rejeita H0 a 5\% (1) & Não \\
\hline M4 2000 (90-08) & Não rejeita H0 a $10 \%$ (1) & Não rejeita H0 a 10\% (1) & Não \\
\hline M4-1 2000 (90-08) & Não rejeita H0 a $10 \%$ (7) & Não rejeita H0 a 10\% (1) & Não \\
\hline FBKF real (99-13) & Não rejeita H0 a 10\% (1) & Não rejeita H0 a $10 \%$ (1) & Não \\
\hline $\begin{array}{l}\text { Deflator de preços dos } \\
\text { bens de capital (99-13) }\end{array}$ & Não rejeita H0 a 10\% (2) & Não rejeita H0 a 10\% (3) & Não \\
\hline ICEI (99-13) & Rejeita H0 a $10 \%$ (1) & Rejeita H0 a $10 \%$ (1) & Sim \\
\hline Selic real (99-13) & Não rejeita H0 a $10 \%$ (1) & Não rejeita H0 a 10\% (5) & Não \\
\hline Selic real (94-13) & Não rejeita H0 a 10\% (4) & Não rejeita H0 a 10\% (1) & Não \\
\hline Selic real-1 (94-13) & Não rejeita H0 a 10\% (1) & Não rejeita H0 a 10\% (1) & Não \\
\hline $\begin{array}{l}\text { Número de empresas } \\
(99-13)\end{array}$ & Não rejeita $\mathrm{H} 0$ a $10 \%$ (1) & Não rejeita H0 a 5\% (1) & Não \\
\hline $\begin{array}{l}\text { Crédito ao Setor } \\
\text { Privado/PIB (94-13) }\end{array}$ & Não rejeita H0 a 10\% (1) & Não rejeita H0 a 10\% (1) & Não \\
\hline $\begin{array}{l}\text { (Crédito ao Setor } \\
\text { Privado/PIB)-1 }(94-13)\end{array}$ & Não rejeita H0 a 10\% (1) & Não rejeita H0 a 10\% (1) & Não \\
\hline
\end{tabular}

* H0: existe raiz unitária (série integrada de ordem maior que zero) contra hipótese alternativa de estacionariedade em uma tendência linear ou de estacionariedade em média (sem tendência linear). 